\title{
КОМИССИОННАЯ ТОРГОВЛЯ В УСЛОВИЯХ АВТОМАТИЗАЦИИ УЧЕТНОГО ПРОЦЕССА (УЧЕТ И НАЛОГООБЛОЖЕНИЕ У КОМИТЕНТА)
}

\author{
(c) 2020 Куликова Ирина Владимировна \\ кандидат экономических наук, доцент кафедры экономики и финансов \\ Алтайский филиал Российской академии народного хозяйства и государственной службы \\ при Президенте РФ, Россия, Барнаул \\ E-mail: irenkulikova_82@mail.ru
}

Некоторые хозяйствующие субъекты применяют при ведении хозяйственной деятельности посреднические договоры, при этом самым популярным является договор комиссии. В данной статье автором изложены вопросы бухгалтерского учета и налогообложения операций комиссионной торговли у комитента в условиях автоматизации учетного процесса.

Ключевые слова: договор комиссии, комитент, комиссионер, бухгалтерский учет, налогообложение, реализация товаров.

Реализация товаров по договору комиссии достаточно распространенная операция в практике осуществления деятельности хозяйствующими субъектами. В условиях существующего разнообразия на рынке реализовать свой товар становится подчас затруднительно. В частности, это касается небольших торговых фирм, испытывающих нехватку оборотных средств.

Согласно нормам п. 1 ст. 990 [1] ГК РФ по договору комиссии одна сторона сделки - комиссионер по распоряжению другой стороны - комитента принимает на себя обязанности за определенное вознаграждение произвести одну или несколько сделок от своего имени, но за счет комитента. Стоит отметить, что при совершении комиссионером сделки с третьим лицом, права и обязанности возникают у комиссионера, несмотря на то, что в сделке принимает участие комитент (п. 1 ст. 990 ГК РФ). Договор комиссии предписывает комитенту уплатить вознаграждение в установленном порядке и размере. Имущество, поступившее к комиссионеру от комитента на ответственное хранение, является собственностью последнего. По завершении исполнения поручения комитента комиссионер должен предоставить соответствующий отчет, и передать полученное имущество по договору комиссии.

В свою очередь, комитент кроме уплаты вознаграждения в определенных случаях обязан возместить расходы комиссионеру на исполнение условий договора комиссии (ст. 1001 ГК РФ). При заключении договора комиссии на продажу товара для учета посреднических операций ко- митенты используют счет 45 «Товары отгруженные». Данный счет предназначен для отражения информации о движении товаров, выручка от реализации которых некоторое время не может быть признана в учете хозяйствующего субъекта. По дебету счета 45 «Товары отгруженные» отражается фактическая производственная себестоимость продукции и расходы по отгрузке в корреспонденции с кредитом счета 43 «Готовая продукция». В целях отражения учет расчетов комитента с посредником-комиссионером применяется счет 76 «Расчеты с разными дебиторами и кредиторами». Если для ведения учета используется программа «1С: Бухгалтерия», то потребуется произвести первоначальную настройку. В разделе «Администрирование» в настройках функциональности на вкладке «Торговля» необходимо установить флаг напротив пункта «Продажа товаров или услуг через комиссионеров (агентов)». Только после проведения указанных настроек у пользователей программы появится возможность создавать документ «Отчет комиссионера (агента) о продажах», а при оформлении договоров с контрагентами выбирать вид «С комиссионером (агентом) на продажу» [2].

Кроме того, при оформлении договоров с комиссионером в программе обязательно устанавливается способ определения суммы комиссионного вознаграждения: определенный процент от стоимости реализованных товаров, услуг на комиссионной основе; процент от разницы между суммой продаж и поступления; не определяется. Факт передачи комиссионного товара от комитента посреднику в программе «1С: Бух- 
галтерия» оформляется при помощи документа «Реализация (товары, услуги, комиссия)», который при проведении формирует бухгалтерскую проводку Дебет 45.01 «Покупные товары отгруженные» - Кредит 41.01 «Товары на складах».

Комиссионер учитывает поступившие товары на специальных забалансовых счетах 002 «Товарно-материальные ценности, принятые на ответственное хранение» (при приобретении товаров по поручению комитента) либо 004 «Товары, принятые на комиссию» (при продаже товаров, принадлежащих комитенту) по стоимости, согласованной с комитентом с учетом НДС. При отражении комиссионных операций в бухгалтерском учете посредники должны руководствоваться нормами ФСБУ 5/01 «Учет материальнопроизводственных запасов», указывающими на необходимость принятия к учету таких товаров в оценке, предусмотренной договором. После реализации товаров покупателям и получении отчета от посредника (комиссионера) комитент оформляет документ «Отчет комиссионера (агента) о продажах». Указанный документ позволит отразить в учетной системе комитента следующие записи:

- Дебет 90.02.1 «Себестоимость продаж по деятельности с основной системой налогообложения» Кредит 45.01 «Покупные товары отгруженные» - списана себестоимость проданных товаров;

- Дебет 76.09 «Прочие расчеты с разными дебиторами и кредиторами» Кредит 90.01.1 «Выручка по деятельности с основной системой налогообложения» - отражена выручка от реализации товаров по договору комиссии;

- Дебет 90.03 «Налог на добавленную стоимость» Кредит 68.02 «Налог на добавленную стоимость» - отражена сумма НДС от реализации товаров;

- Дебет 60.01 «Расчеты с поставщиками и подрядчиками» Кредит 76.09 «Прочие расчеты с разными дебиторами и кредиторами»- отражена сумма комиссионного вознаграждения с учетом НДС;

- Дебет 44.01 «Издержки обращения в организациях, осуществляющих торговую деятельность» Кредит 60.01 «Расчеты с поставщиками и подрядчиками» - отражена сумма комиссионного вознаграждения без НДС;

- Дебет 19.04 «НДС по приобретенным услугам» Кредит 60.01 «Расчеты с поставщиками и подрядчиками» - отражена сумма НДС с комис- сионного вознаграждения.

Таким образом, только на дату получения отчета о продаже товаров комиссионером комитент признает в учетной системе выручку как доход от обычных видов деятельности (ФСБУ 9/99 «Доходы организации») и отражает его на счете 90.01 «Выручка».

Рассмотрим на примере (табл. 1). Организация (комитент) ООО «Смарт» заключила договор комиссии с организацией (комиссионером) ООО «Интер». Организация (комитент) отгрузила на склад посредника товары для последующей реализации на сумму 2100000 руб. (в том числе НДС 20\%). В текущем месяце были проданы не все товары. Стоимость отгруженных товаров в учете комитента составляет 2700000 руб. Агентское вознаграждение по соглашению сторон составляет 10\% от выручки.

Остановимся более подробно на особенностях налогообложения при совершении комиссионных операций. Процесс реализации товаров (работ, услуг) в результате, которого происходит переход права собственности является объектом налогообложения в части НДС (ст. 39, ст. $146 \mathrm{HK}$ РФ) [3]. Однако при отгрузке товаров комитентом на склад комиссионера право собственности к хозяйствующему субъекту не переходит, следовательно, не возникает необходимости исчислить и уплатить НДС.

При реализации товаров посредником покупателям налоговое законодательство обязывает комитента исчислять НДС к уплате в бюджет, так как именно он является собственником (п. 1 ст. 996 ГК РФ). Если договором не предусмотрены авансовые платежи, тогда налогооблагаемая база определяется на дату реализации товаров посредником покупателю (пп. 1 п. 1 ст. 167 НК $\mathrm{P} \Phi)$.

Налоговое законодательство определяет, что моментом признания налоговой базы по НДС у комитента (принципала) признается наиболее ранняя из дат:

- дата реализации товаров (работ, услуг);

- дата поступления денежных средств (полная оплата или частичная оплата) (п. 1 ст. 167 HK $\mathrm{P} \Phi)$.

Комитент определяет налоговую базу по НДС как стоимость товаров, рассчитанную исходя из цены их реализации комиссионером покупателям без учета НДС. Согласно требованиям НК РФ в общем порядке налогоплательщики НДС при реализации товаров покупателям должны 
Таблица 1. Корреспонденция счетов по учету комиссионных операций у комитента ОоО «Смарт» (договор на продажу товаров)

\begin{tabular}{|c|c|c|c|c|c|}
\hline \multirow{2}{*}{$\begin{array}{l}\text { № } \\
\Pi / \Pi\end{array}$} & \multirow{2}{*}{$\begin{array}{l}\text { Содержание хозяй- } \\
\text { ственной операции }\end{array}$} & \multirow{2}{*}{ Сумма, руб. } & \multicolumn{2}{|c|}{ Корреспонденция счетов } & \multirow{2}{*}{$\begin{array}{c}\text { Документ в } \\
1 \mathrm{C}\end{array}$} \\
\hline & & & дебет & кредит & \\
\hline \multicolumn{6}{|c|}{16 июня 2019 г. } \\
\hline 1. & $\begin{array}{l}\text { Отгружены товары } \\
\text { комитентом комисси- } \\
\text { онеру }\end{array}$ & 2700000 & $\begin{array}{l}45.01 \text { «Покупные то- } \\
\text { вары отгруженные» }\end{array}$ & $\begin{array}{c}41.01 \text { «Товары на } \\
\text { складах» }\end{array}$ & $\begin{array}{l}\text { «Реализация } \\
\text { (товары, услу- } \\
\text { ги, комиссия)» }\end{array}$ \\
\hline \multicolumn{6}{|c|}{28 июня 2019 г. } \\
\hline 2. & $\begin{array}{l}\text { Отражена выручка от } \\
\text { реализации товаров } \\
\text { согласно отчету комис- } \\
\text { сионера }\end{array}$ & 2100000 & $\begin{array}{c}76.09 \text { «Прочие расче- } \\
\text { ты с разными дебито- } \\
\text { рами и кредиторами» }\end{array}$ & $\begin{array}{c}90.01 .1 \text { «Выручка } \\
\text { по деятельности с } \\
\text { основной системой } \\
\text { налогообложения» }\end{array}$ & \multirow{6}{*}{$\begin{array}{l}\text { Отчет комис- } \\
\text { сионера (аген- } \\
\text { та) о продажах }\end{array}$} \\
\hline 3. & $\begin{array}{l}\text { Отражена сумма НДС с } \\
\text { реализации }\end{array}$ & 350000 & $\begin{array}{c}90.03 \text { «Налог на } \\
\text { добавленную стои- } \\
\text { мость» }\end{array}$ & $\begin{array}{c}68.02 \text { «Налог на } \\
\text { добавленную стои- } \\
\text { мость» }\end{array}$ & \\
\hline 4. & $\begin{array}{l}\text { Списана себестоимость } \\
\text { реализованных товаров }\end{array}$ & 1990000 & \begin{tabular}{|c|} 
90.02.1 «Себестои- \\
мость продаж по дея- \\
тельности с основной \\
системой налогоо- \\
бложения» \\
\end{tabular} & $\begin{array}{l}45.01 \text { «Покупные то- } \\
\text { вары отгруженные» }\end{array}$ & \\
\hline 5. & $\begin{array}{l}\text { Отражена задолжен- } \\
\text { ность по комиссионно- } \\
\text { му вознаграждению }\end{array}$ & 210000 & \begin{tabular}{|c|} 
60.01«Расчеты с \\
поставщиками и под- \\
рядчиками» \\
\end{tabular} & \begin{tabular}{|c|}
76.09 «Прочие расче- \\
ты с разными дебито- \\
рами и кредиторами»
\end{tabular} & \\
\hline 6. & $\begin{array}{l}\text { Отражена сумма комис- } \\
\text { сионного вознагражде- } \\
\text { ния в составе затрат без } \\
\text { НДС }\end{array}$ & 175000 & 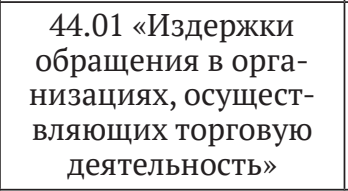 & $\begin{array}{c}60.01 \text { «Расчеты с } \\
\text { поставщиками и под- } \\
\text { рядчиками» }\end{array}$ & \\
\hline 7. & $\begin{array}{l}\text { Отражен предъявлен- } \\
\text { ный комиссионером } \\
\text { НДС }\end{array}$ & 35000 & $\begin{array}{c}19.04 \text { «НДС по приоб- } \\
\text { ретенным услугам» }\end{array}$ & $\begin{array}{c}60.01 \text { «Расчеты с } \\
\text { поставщиками и под- } \\
\text { рядчиками» }\end{array}$ & \\
\hline \multicolumn{6}{|c|}{28 июня 2019 г. } \\
\hline 8. & $\begin{array}{l}\text { Регистрация счета- } \\
\text { фактуры на сумму } \\
\text { комиссионного возна- } \\
\text { граждения }\end{array}$ & 35000 & $\begin{array}{c}68.02 \text { «Налог на } \\
\text { добавленную стои- } \\
\text { мость» }\end{array}$ & $\begin{array}{c}19.04 \text { «НДС по приоб- } \\
\text { ретенным услугам» }\end{array}$ & $\begin{array}{l}\text { Счет-фактура } \\
\text { полученный }\end{array}$ \\
\hline \multicolumn{6}{|c|}{9 июля 2019 г. } \\
\hline 9. & $\begin{array}{l}\text { Получена выручка от } \\
\text { комиссионера за выче- } \\
\text { том вознаграждения }\end{array}$ & 1890000 & 51 «Расчетные счета» & $\begin{array}{c}76.09 \text { «Прочие расче- } \\
\text { ты с разными дебито- } \\
\text { рами и кредиторами» }\end{array}$ & $\begin{array}{c}\text { Поступление } \\
\text { на расчетный } \\
\text { счет }\end{array}$ \\
\hline
\end{tabular}

предъявить им НДС, выставив счет-фактуру в течение пяти календарных дней начиная со дня отгрузки (с. 168, ст. 169 НК РФ).

Между тем, несмотря на то, что собственником является комитент, товары реализуются покупателям от имени комиссионера (п. 1 ст. 990 ГК РФ), следовательно, комиссионер выставляет покупателю счет-фактуру от своего имени. Затем данные по выставленным счетам-фактурам комиссионер передает комитенту, который перевыставляет в адрес посредника счета-фактуры с аналогичными реквизитами, но от своего имени.

Зачастую комитент получает от комиссионера несколько счетов-фактур, выставленных за один день двум и более покупателям, которые необходимо перевыставить. В этом случае комитент имеет возможность выставить единый (сводный) счет-фактуру. Перевыставленные счета-фактуры подлежат обязательной регистрации в книге продаж комитента в том налоговом периоде, в котором была произведена реализация товаров комиссионером покупателю либо получен аванс.

Поступление выручки на расчетный счет комитента от комиссионера за вычетом комиссионного вознаграждения не приводит к возникновению налоговых обязательств по НДС у субъекта хозяйствования.

При использовании различных режимов на- 
логообложения комитентами и комиссионерами, последние могут одновременно осуществлять реализацию товаров, относящихся к разным режимам налогообложения, то есть облагаемых и необлагаемых НДС. Если комитент находится на общей системе налогообложения и является плательщиком НДС, а посредник использует УСН или ЕНВД, то есть не уплачивает НДС, то реализация собственного товара производится без НДС, а комиссионного будет облагаться НДС.

Стоимость товаров, переданных комиссионеру, не учитывается для целей налогообложения прибыли, поскольку указанная операция не влияет на величину доходов и расходов, то есть отсутствует факт реализации товаров (работ, услуг) (п. 1 ст. 249 НК РФ). Реализация товаров комитента предопределяет его обязанность признать в качестве налогооблагаемых доходов сумму поступившей выручки от покупателей без учета НДС, а в составе расходов стоимость переданных посреднику товаров.

Следует отметить, что между хозяйствующими субъектами может быть заключен договор не на продажу, а на приобретение товаров для комитента (принципала). Приобретенные через посредника товары комитент может получить от агента или непосредственно от поставщиков. Комитент принимает к бухгалтерскому учету товар, приобретенный через посредника, согласно требованиям ФСБУ 5/01 «Учет материальнопроизводственных запасов», то есть по фактической стоимости за исключением НДС и других возмещаемых налогов. Таким образом, фактическая стоимость таких товаров может складываться из расходов, связанных с приобретением (погрузка, разгрузка, транспортировка, хранение), а также суммы комиссионного вознаграждения, уплаченного агенту (посреднику).

Если по поручению комитента приобретается оборудование, которое в дальнейшем предполагается использовать в качестве основного средства, то для отражения его стоимости следует руководствоваться нормами ФСБУ 6/01 «Учет основных средств».

Отчет комиссионера (агента) служит основанием для отражения в налоговом учете стоимости поступивших от посредника товаров, а его вознаграждение может быть учтено в составе расходов текущего налогового периода (ст. 320 НК РФ). Полученный от поставщика счет-фактуру комиссионер перевыставляет комитенту, указывая в качестве даты - дату счета-фактуры

Таблица 2. Корреспонденция счетов по учету комиссионных операций у комитента ОоО «Смарт» (договор на приобретение товаров)

\begin{tabular}{|c|c|c|c|c|c|}
\hline \multirow{2}{*}{$\begin{array}{l}\text { № } \\
\text { П/П }\end{array}$} & \multirow{2}{*}{$\begin{array}{l}\text { Содержание хозяй- } \\
\text { ственной операции }\end{array}$} & \multirow{2}{*}{ Сумма, руб. } & \multicolumn{2}{|c|}{ Корреспонденция счетов } & \multirow{2}{*}{$\begin{array}{c}\text { Документ в } \\
1 \mathrm{C}\end{array}$} \\
\hline & & & дебет & кредит & \\
\hline \multicolumn{6}{|c|}{5 ноября 2019 г. } \\
\hline 1. & $\begin{array}{l}\text { Перечислено с расчет- } \\
\text { ного счета агенту на } \\
\text { приобретение товаров }\end{array}$ & 360000 & 76.01 & 51 & $\begin{array}{l}\text { Платежное } \\
\text { поручение }\end{array}$ \\
\hline \multicolumn{6}{|c|}{10 ноября 2019 г. } \\
\hline 2. & $\begin{array}{l}\text { От агента поступили } \\
\text { товары, приобретен- } \\
\text { ные по поручению }\end{array}$ & 300000 & 41.01 & 76.09 & \multirow{3}{*}{$\begin{array}{c}\text { Поступление (акты, } \\
\text { накладные) }\end{array}$} \\
\hline 3. & $\begin{array}{l}\text { Учтен НДС по посту- } \\
\text { пившим товарам }\end{array}$ & 60000 & 19.03 & 76.09 & \\
\hline 4. & Зачтен аванс & 360000 & 76.09 & 76.09 & \\
\hline 5. & НДС принят к вычету & 60000 & 68.02 & 19.03 & Счет-фактура \\
\hline \multicolumn{6}{|c|}{10 ноября 2019 г. } \\
\hline 6. & $\begin{array}{l}\text { Сумма агентского воз- } \\
\text { награждения учтена в } \\
\text { стоимости товаров }\end{array}$ & 15000 & 41.01 & 76.09 & \multirow{2}{*}{$\begin{array}{c}\text { Поступление (акты, } \\
\text { накладные) } \\
\text { Поступление } \\
\text { дополнительных } \\
\text { расходов }\end{array}$} \\
\hline 7. & $\begin{array}{l}\text { Учтен НДС по агентско- } \\
\text { му вознаграждению }\end{array}$ & 3000 & 19.04 & 76.09 & \\
\hline 8. & НДС принят к вычету & 3000 & 68.02 & 19.04 & Счет-фактура \\
\hline \multicolumn{6}{|c|}{15 ноября 2019 г. } \\
\hline 9. & $\begin{array}{l}\text { Перечислено агентское } \\
\text { вознаграждение }\end{array}$ & 18000 & 76.09 & 51 & $\begin{array}{l}\text { Платежное } \\
\text { поручение }\end{array}$ \\
\hline
\end{tabular}


поставщика и его данные. Помимо этого комиссионер передает принципалу копию счетафактуры, полученного им от поставщика.

Рассмотрим на примере (табл. 2). Организация ООО «Смарт» (принципал) заключила агентский договор от 31.10.2019 с ООО «Интер» (агент). Агент по поручению принципала обязуется приобрести партию товара на общую сумму 360000 руб. (в том числе НДС 20\% - 60000 руб.). Агент выступает от своего имени, но за счет принципала. Вознаграждение агента составляет 5\% от суммы агентского договора, то есть 18000 руб (в том числе НДС 3000 руб.).

Таким образом, для комитента неотъемлемым условием, обеспечивающим правильность расчетов и своевременность погашения налоговых обязательств перед бюджетом, является эффективно функционирующая система документооборота с комиссионером.

\section{Библиографический список}

1. Гражданский кодекс Российской Федерации (часть вторая) URL: http://www.consultant.ru/document/cons_ doc_LAW_9027/cca276287b4e78f6bd949d7e1aef14a463bd0f2e/

2. Информационная система 1C: ИTC URL: https://its.1c.ru

3. Налоговый кодекс Российской Федерации (часть вторая) URL: http://www.consultant.ru/document/cons_doc_ LAW_28165/ 